\title{
LOS CAMBIOS SOCIO-ECONÓMICOS Y EL MEDIO AMBIENTE: CUBA. PRIMERA MITAD DEL SIGLO XIX
}

\author{
POR \\ JOSEF OPATRNÝ \\ Universidad Carolina de Praga
}

El gran desarrollo de la industria azucarera en Cuba en la primera mitad del siglo XIX influyó de forma decisiva en el medio ambiente. La demanda acuciante de madera y de mano de obra esclava para los ingenios pasaron a ser el tema de preocupación entre algunos criollos de la élite. Ambos problemas aparecen unidos en sus peticiones para frenar la deforestación.

Desde hace mucho tiempo, la historiografía cubana considera el fin del siglo XVIII y los primeros decenios del siglo XIX como un período clave de la historia de Cuba. Subraya, ante todo, los cambios profundos que se produjeron en la economía de la colonia y el desarrollo en la esfera social. Algunos autores destacan el papel que en estos cambios tuvo la ocupación de La Habana por los ingleses en 1762 (1), mientras que otros no aceptan plenamente esta concepción del impulso directo del ingreso al mercado mundial en el desarrollo de Cuba y enfocan el problema desde otras perspectivas, destacando las causas

Este texto fue presentado en el 48 Congreso de Americanistas en Estocolmo.

(1) Comp. por ejemplo, J. LE RIVEREND, Historia económica de Cuba. La Habana, Escuela de Comercio Exterior, 1963, pág. 131. 
internas de este proceso donde el impacto de los comerciantes ingleses desempeñó tan sólo el papel de catalizador (2).

A fines del siglo xviII se puede observar en la colonia un gran auge de la industria azucarera. No cabe duda que este desarrollo tuvo una relación estrecha con la revolución en la colonia francesa de Saint Domingue donde las luchas entre los esclavos y los esclavistas habían liquidado totalmente las plantaciones de caña y los ingenios. El espacio vacío que surgió en el mercado de azúcar mundial -junto con su demanda creciente- ayudaron a la sacarocracia naciente de Cuba a ocupar un lugar más importante en la economía y en la sociedad colonial (3). Como hizo constar Manuel Moreno Fraginals, Cuba contaba con cuatro condiciones para convertirse en el primer productor de azúcar en el mundo: primero, tierras fértiles y convenientes para la producción de caña de azúcar; segundo, bosques abundantes que proporcionasen madera no sólo para la construcción de trapiches y edificios, sino también para suministrar combustible para las pailas en los ingenios; tercero, ganado abundante para la alimentación de la mano de obra esclava y como fuerza motriz del ingenio, y cuarto, instrumentos de trabajo (4). A pesar de los obstáculos que frenaron el crecimiento de los cañaverales e ingenios, la colonia iba produciendo cada año una cantidad cada vez mayor de azúcar (5).

La expansión de la producción del azúcar estuvo motivada por dos factores, por una parte el creciente número de plantaciones $\mathrm{y}$, por la otra, el aumento de la capacidad productiva del ingenio. No obstante, ambos factores tenían sus límites. El primero de ellos fue el problema del transporte del producto a los puertos; el segundo, la organización del trabajo y de la vida en

(2) Comp. J. Robert McNeIll, Atlantic Empires of France and Spain. Louisburg and Havana, 1700-1763. University of North Carolina Press, Chapel Hill and London, 1985, o L. MARrero, Cuba: economía y sociedad, vols. 6-8, Madrid, Editorial Playor, 1978-1980.

(3) Sobre este problema ver esp. F. KNIGHT, Slave Society in Cuba During the Nineteenth Century. Madison, The University of Wisconsin Press, 1970.

(4) M. Moreno Fraginals, El Ingenio. Complejo económico social cubano del azúcar. La Habana, Editorial de Ciencias Sociales, 1978, t. I, págs. 15-18.

(5) Comp. los datos estadísticos en M. TORRENTE, Bosquejo económico político de la isla de Cuba. Madrid, Imprenta de D. Manuel Pita, 1852, t. I, pág. 170.

R. I., 1996, n. ${ }^{\circ} 207$ 
la plantación y en el ingenio. Históricamente, el centro de la industria azucarera cubana era La Habana y sus alrededores, de donde las plantaciones se iban expandiendo ante todo en dos rumbos: al interior, donde ya antes había existido un centro azucarero en Santa María del Rosario; y a lo largo de la costa donde Mariel y Matanzas despertaban esperanza en cuanto a las posibilidades portuarias.

La mencionada expansión de las plantaciones no fue causada sólo por el afán de los terratenientes en ampliar sus propiedades, sino también por el agotamiento de los terrenos y, ante todo, por la liquidación casi total de los bosques en los alrededores de la ciudad. Por eso se puede observar el proceso de abandono de los terrenos agotados en la cercanía de La Habana y la expansión de la zona azucarera a mayor distancia de las murallas y muelles. No obstante, la fundación de nuevas plantaciones, igual que la limpieza del terreno con el fin de prepararlo para la caña eran, ilegales. Las leyes coloniales, hasta 1805, negaban a los propietarios de la tierra disponer libremente de los árboles, ya que los bosques estaban protegidos por las leyes como almacén de madera para el astillero habanero donde construyeron más de cien barcos de primera (6). Una gran cantidad de la madera cubana de alta calidad fue exportada también a España u otros países europeos. Es un hecho notorio que este comercio tuvo una larga tradición: a partir de la construcción de El Escorial, los arquitectos españoles utilizaban las maderas preciosas cubanas -caobas, cedros, dagames, etc.-. Sin embargo, al final del siglo xviII, y después en el siglo XIX, la sacarocracia devastó grandes áreas forestadas incendiando miles de caballerías de los bosques.

La técnica de preparación de los nuevos terrenos para sembrar la caña fue muy simple. Los esclavos o los campesinos especializados para este tipo de trabajo penetraban en el bosque con machetes cortando los bejucos y enredaderas, tras ellos, otros trábajadores derrumbaban los árboles centenarios, $\mathrm{y}$, transcurrido un mes, lo quemaban todo sin utilizar la madera para algo útil. Sobre este proceso son muy ilustrativos los

(6) Comp. Douglas G. INGLIS, «The Spanish Naval Shipyard at Havana in the Eighteenth Century", en: New Aspects of Naval History. Baltimore, Selected Papers from the 5th Naval History Symposium, 1985, págs. 47-58. 
comentarios de Miguel Rodríguez-Ferrer, aparecidos en las $\mathrm{Me}$ morias de la Sociedad Económica de La Habana:

"Cuando se comienzan á abrir tèrenos para establecer un ingenio, elegidos ya los que se creen suficientes, toda la preparación que se hace es introducir las hachas en los bosques y abatir desde el arbusto débil y la inútil liana, hasta los corpulentos troncos y las más preciosas maderas; después de algunos días de esta operación (30 ó 40 días), cuando ya se consideran secos los ramajes, el voraz incendio viene a concluir la obra de devastación, sucediendo á veces que sólo quedan los gruesos troncos, y otras, que hacen preciso volver al terreno, amontonar los restos y volver á dar candela, a fin de destruir aquellos para la siembra. Este es precisamente el mismo sistema (si puede llamarse tal, la ruina de los elementos de tan abundante como preciosa riqueza); esta es la operación que se hace para preparar espacio en que verificar el planteo de las cañas» (7).

(7) M. Rodriguez-FerRer, Naturaleza y civilización de la grandiosa isla de Cuba o estudios variados y científicos, al alcance de todos y otros históricos, estadísticos y políticos. Madrid, 1876, Imprenta de J. Noguera, Parte Primera, pág. 691. Sobre la "tecnología» de la deforestación ver pág. 685 y sigs., especialmente pág. 690 y sigs. En cuanto a este proceso el autor dice: "Acabo de indicarlo: estas causas se dividen en ordinarias, normales ó regularizadas, y en extraordinarias ó anormales. Pertenecen á las primeras aquellos preliminares ó prácticas rurales, que desde la conquista se vienen aplicando en Cuba, por la condición de su agricultura casi errante, como explicaré mejor en otra parte, cuando aborde entre las etapas de su civilización los últimos adelantos de su agricultura ingeniera, porque el agricultor cubano no ha librado nunca su cultivo al sistema intensivo, sino que siempre lo ha hecho sobre el extensivo. Siempre ha tumbado porción de bosque nuevo, para aprovechar sólo un cierto tiempo su virginal jugo. Cuando se ha depauperado la tierra ó consumido sus sustancias y sales, ha llevado su potrero, su cafetal ó ingenio más allá, siempre buscando los despojos del bosque tumbado y quemado. El sistema, por lo tanto, no ha podido ser más simplificado; recoger las primicias del suelo por un número de años, abandonarlo por otro nuevo para recibir sus extraordinarios productos con igual facilidad, sin necesidad de ararlo ni abonarlo; é inútil es decir, por lo tanto, que á tan inmediato bien no cabe predicación contra tal conveniencia individual, por más que pueda ser más inconveniente para la colectividad y para ciertas consecuencias climatológicas y forestales, con un sistema que no puede ser peor. Y lo más sensible es, que si éste se hubiera remontado sólo á los tiempos de la conquista, en que la fuerza personal del conquistador vino á suplir la inteligencia de una 
Por estos medios se fundó en los primeros decenios del siglo xIx el nuevo centro azucarero en Matanzas que influyó sustancialmente en el desarrollo de la industria azucarera cubana ya en los años veinte del siglo XIX. «En 1827 produce ya el $25 \%$ del azúcar cubano. Diez años más tarde presenta nuevas zonas de tan amplio desarrollo que es necesario crear la Tenencia de Cárdenas. En 1837 se funda Colón, que veinte años más tarde es la primera zona azucarera de Cuba» (8). Un caso parecido, aunque de menor importancia en cuanto al volumen de producción del azúcar, fue la región de Trinidad, donde José Borrel fundó el famoso ingenio de Guáimaro que en el año 1827 produjo 943 toneladas de azúcar, la mayor cantidad no sólo en Cuba, sino en todo el mundo de ese tiempo. Un problema serio de las plantaciones más remotas de la costa o del río navegable (estos ríos no fueron muy numerosos en la colonia, especialmente en las regiones azucareras) lo representaba el transporte del azúcar y las mieles al mercado. En el período observado, la mayoría de los caminos en Cuba fue tipo camino de recuas, es decir las mercancías se transportaban mediante una hilera de mulos. No obstante, tales comunicaciones no sirvieron en las condiciones nuevas. La producción de los grandes ingenios requería al menos caminos carreteros, siendo los tiros de bueyes uncidos en grandes carretas que transportaban las pesadas cajas de azúcar. No es por ca-

sociedad incipiente, disculpable habría sido el sistema. Pero como era de esperar, acostumbrados los primeros ocupantes á fiarlo todo á la sola fuerza; en alivio de los brazos indios, fueron introducios los africanos ó esclavos, y ya la inteligencia quedó para mandar siervos, no para ilustrar nuevos y mejores métodos. La fuerza, por lo tanto, ha venido sancionando el sistema, y hé aquí el procedimiento que por desgracia se ha venido observando, y lo que es peor, que continuará sin remedio, mientras que no cuente la isla con una población acreciente que pueda detener la condición trashumante de su agricultura, siempre en busca de terrenos frescos por sus bosques, para fundar nuevas fincas. Veamos ahora cuáles son estos preliminares, cuando ya se poseen ó se han comprado los montes firmes para formar aquéllas, y de qué modo son arrasados, primero por el cortante machete, después por la formidable hacha, y por el último, por el voraz incendio.», pág. 689.

(8) M. Moreno Fraginals, [4], pág. 141. Sobre el desarrollo de la región matancera comp. especialmente L. W. BERGAD, Cuban Rural Society in the Nineteenth Century. The Social and Economic History of Monoculture in Matanzas. Princeton University Press, Princeton, 1990. 
sualidad, que exactamente en los años noventa aparecieran varios estudios sobre la necesidad de la construcción del sistema de caminos en la isla (9). Sin embargo, tampoco este tipo de caminos pudo resolver dicho problema y, por eso, apareció el plan de construir el canal de los Güines, inspirado, sin duda, en la experiencia europea y estadounidense de los portavoces de la sacarocracia criolla, y que fue apoyado por Francisco Arango y Parreño. Este proyecto, mencionado por Alejandro de Humboldt (10), fue discutido en la sociedad cubana hasta el año de 1834 sin resultados prácticos. Uno de los factores importantes que ayudaron al fracaso del proyecto del canal fue, sin duda, un proyecto más perspectivo $\mathrm{y}$, ante todo más económico: la idea de construir en la isla los caminos de hierro (recuérdese que Cuba fue el primer país latinoamericano donde se construyó una línea de ferrocarril, en 1837) (11).

(9) Comp., por ejemplo, Nicolás CALvo y O’FARrill, Memoria sobre los medios que convendría adoptar para que tuviese La Habana los caminos necesarios. La Habana, Imprenta de la Capitanía General, 1795, o Juan Tomás DE JAÚREGUI, Memoria sobre proporcionar arbitrios para la construcción de caminos en esta jurisdicción. La Habana, Esteban Boloña, 1795. No obstante, la obra más famosa de esta índole fue publicada en el año 1830 por José Antonio SACO, "Memoria sobre caminos en la isla de Cuba", en: Acta de las juntas generales que celebró la Real Sociedad Económica de Amgios del País de La Habana, en los dias 14, 15 y 16 de diciembre de 1829. La Habana, Oficina de las viudas Arazoza y Soler, 1830, donde el autor hizo constar: "El Gobierno como amigo y protector del pueblo debe proponer a acalorar todo proyecto que redunde en beneficio común. ¿Y cuál de más importancia se puede presentar en la isla de Cuba? Ciertamente que ninguno; y es de tal naturaleza, que aun cuando se considerasen distintos el interés del pueblo y el de Gobierno, todavía éste sacaría grandes ventajas. La pronta y fácil comunicación con que puede circular sus órdenes, la rapidez con que puede mover sus tropas de un punto á otro, y la mayor renta que entrará en sus arcas con el impulso que se da á la agricultura y demas ramos industriales, son las consideraciones tan claras que saltan al entendimiento aun del hombre más obcecado.», pág. 266. Juntamente con este estudio o memoria, en el mismo volumen de Actas se publicaron otros materiales sobre este problema, comp. las «Memorias de Tranquilino Sandalio de Noa», Ibid., págs. 269-295, o de José Segundo Izquierdo, Ibid., págs. 297-323.

(10) Alejandro von Humboldt, Ensayo político sobre la isla de Cuba. La Habana, Publicaciones del Archivo Nacional de Cuba, 1960, pág. 262 y sigs.

(11) No sorprende que esta línea conectó La Habana con Bejucal, situado en una región azucarera muy prometedora, y que ya antes de acabar esta construcción aparecieron nuevos proyectos de como multiplicar la extensión

\section{R. I., 1996, n.o 207}


Para la historiografía clásica, igual como para la contemporánea, el ferrocarril en Cuba fue un fenómeno que cambió completamente la producción azucarera (12). Comparando la situación en los Estados Unidos donde la línea transcontinental abrió campos vírgenes, el ferrocarril en Cuba siguió los caminos carreteros entre los cañaverales, acercándolos no sólo a los puertos, sino también a los ingenios, y formando durante dos decenios una densa red. Las líneas férreas comunicaron el interior del país con la costa en algunas regiones de la isla y formaron inmensas áreas azucareras (13). Las llanuras en torno a La Habana fueron atravesadas por la línea hasta Guanajay, Macagua y Colón. Ramales más cortos conectaron esta artería de industria azucarera con Batabanó, Jovellanos, Cárdenas y·Júcaro. En el área de Cienfuegos existió también una combinación de las vías principales con los terminales en los puertos y de los ramales que posibilitaron la expansión de los cañaverales en toda la región desde Cruces hasta La Esperanza, San Marcos, etc. El último gran centro azucarero estaba en Oriente, donde aparecieron las líneas Santiago-Santo Cristo, Cobre-Punta de Sal y el ferrocarril de Guantánamo.

de «los caminos de hierro». Como no olvidó apuntar J. A. Saco, la entrada del ferrocarril en Güines significó una disminución del $75 \%$ en los costos de transporte. Comp. José Antonio SACO. «La supresión del tráfico de esclavos africanos en la isla de Cuba examinada en relación a su agricultura y a su seguridad", en: Colección de papeles científicos, históricos, políticos y de otros ramos sobre la isla de Cuba, ya publicados, ya inéditos por Don José Antonio Saco. París, Imprenta de D'Aubusson y Kugelmann, 1858, t. II, pág. 111.

(12) Comp. H. E. Friedlaender, Historia económica de Cuba. La Habana, Jesús Montero, 1944; M. Moreno Fraginals, [4]. Hay también estudios especializados sobre el ferrocarril cubano, no obstante, bastante pocos. Comp. O. ZANETTI y A. GÁRcía, Caminos para el azúcar. La Habana, Editorial Ciencias Sociales, 1987. B. Alonso Ballo, M. Herrera Sorzano, E. Moyano, J. SANZ FerNÁNDEZ, M. Socarrás Matos, El camino de hierro de La Habana a Güines. Primer ferrocarril de Iberoamérica. Madrid, Fundación de los Ferrocarriles Españoles, 1987. E. MoYANO BAZZANI, La nueva frontera del azúcar: el ferrocarril y la economía cubana del siglo XIX. Madrid, Consejo Superior de Investigaciones Científicas, 1991.

(13) Los datos sobre el kilometraje creciente, ver en M. TORRENTE, [5], pág. 177.

R. I., 1996, n.o 207 
En el mismo tiempo podemos observar los cambios profundos que se producían en los ingenios. Una parte de la maquinaria siguió fabricándose de madera, a pesar de la importancia que el hierro iba adquiriendo en la industria azucarera. Especialmente la introducción de la máquina de vapor como la fuerza motriz para los trapiches y otras máquinas del ingenio después del año 1819 fue un factor importante en este desarrollo. La introducción gradual de esta máquina motriz (14) influyó sustancialmente también en la opinión de la sacarocracia sobre los bosques como fuentes de combustible. Los productores de caña y del azúcar incurrieron de tal manera en un dilema prácticamente irresoluble. Para poder ampliar las plantaciones necesitaban limpiar el terreno, para la producción del azúcar necesitaban combustible. En la primera mitad del siglo XIX, el combustible más usual era la leña, por ello los terratenientes requerían simultáneamente la libertad de la tala, a la vez de buscar los medios para impedir la liquidación de las reservas de la leña. Hay que decir que en las duras polémicas se formularon también argumentos muy modernos. Ramón de la Sagra pidió la protección de los bosques no sólo como de la riqueza del país, sino como el patrimonio de las futuras generaciones. En su obra sobre la economía y sociedad cubanas, después de criticar la aniquilación irracional de los bosques en la isla, escribió: "Al período actual de madurez de la humanidad, enriquecida con las conquistas de la ciencia, é iluminada en sus empresas, por el sentimiento moral, corresponde la grande y transcendental de explotar la superficie del planeta que habita, del modo más útil y conveniente, no sólo para la generación presente, sino también para

(14) No sorprende mucho que el gran portavoz de la idea de introducción de la máquina de vapor en Cuba fue Wenceslao de Urrutia (compare las páginas respectivas en el libro de Ramón de la SAGRA, Cuba en 1860 o sea cuadro de sus adelantados en la población, la agricultura, el comercio y las rentas públicas. París, Librería de L. Hachette y Ca, 1862, pág. 82 y sigs.), organizador de la compañía para la construcción de la primera línea ferroviaria en la isla. Los altos precios de este tipo de maquinaria y la escasez del capital de la sacocracia frenaron la introducción masiva de las máquinas de vapor. No obstante, los ingenios nuevamente construidos, llamados por M. Moreno Fraginals semimecanizados, se los equipaba siempre de estas máquinas.

\section{R. I., 1996, n.o 207}


las generaciones venideras, lo cual no se conseguirá jamás, si no se subordinan los intereses individuales, efímeros y transitorios, á los intereses generales y eternos de la humanidad entera» (15).

Semejante argumentación presentaron algunos representantes de la sociedad criolla que, hablando sobre el problema de los bosques cubanos, no mencionaron solamente las cuestiones económicas sino también los factores climáticos, etc. "Lo que no puede suplirse», escribió el Conde de Mopox y de Jaruco, "es la acción atmosférica, las lluvias que no encontrando obstáculos que las detengan, ni agentes que las atraigan, pasarán por encima de nuestra Isla larga y angosta, sin fertilizar nuestros campos ni refrescar los ardores de nuestro brillante sol. El terreno se irá esterilizando: privado de frescura y de sombra se convertirá en áridas sábanas, y la fecundidad proverbial de Cuba se verá sustituida por la esterilidad de las arenas africanas» (16).

Por su parte, la administración colonial -ya desde fines del siglo XVIII- se oponía a la presión de la sacarocracia para conseguir libre acceso a la tala de los bosques en la isla argumentando que iba en contra de los intereses de la Corona. Ante todo la Junta de Maderas se opuso con gran resistencia a la aplicación de las leyes del año 1815 que abrían el camino a una tala descontrolada, pero sin ningunos resultados positivos. Las dimensiones que alcanzó la deforestación se manifiestan en la frecuencia con que aparecen en los mapas la denominación "Avenado», durante la primera mitad del siglo xIx. Ya en la década de los cuarenta no existían bosques -y quizá, ni árboles solitarios- no sólo en la inmensa zona azucarera que se extendía desde La Habana hasta Matanzas o Cárdenas, sino también en las regiones de Cienfuegos y Santiago cubier-

(15) Ibidem, pág. 71 y sigs.

(16) El Conde de MoPOX y JARUco, «Ruina de nuestros preciosos montes», en: Memorias de la Sociedad Económica de Amigos del País. La Habana, 30-4-1843, pág. 233. El autor advierte, que esta situación no es necesariamente la pregunta del futuro lejano, diciendo: "Tanto cafetal é ingenio que vemos demoler y las quejas que oímos propalar contra la escasez de cosechas, deben advertirnos de las mudanzas y deterioro de nuestros terrenos, á que es preciso poner coto prontamente.», pág. 234. 
tas al final del segundo decenio por densos bosques con maderas preciosas (17).

Los cambios tan profundos del paisaje y la escasez de madera para la construcción, para la fabricación de cajas para el azúcar, de leña para las casas de caldera y para las máquinas de vapor tuvieron después sus consecuencias. Siguió creciendo la importación de madera de los Estados Unidos (18) y se aumentó la importación del carbón mineral (19). Se cambió la tecnología utilizada en las casas de caldera y desapareció el sistema de un fuego para cada paila por el de un fuego común que calentaba a todas las pailas. Asimismo, se introdujo la caña de Otahití, cuya ventaja no consistía quizá en el más rico guarapo, sino el tamaño de la planta. La altura de la de Otahití llegaba hasta $4 \mathrm{~ms}$ (es decir, fue mucho más alta que la caña criolla o del país que durante el siglo xIx ha sido desplazada en las plantaciones cubanas por las nuevas especies) con circunferencia de hasta $15 \mathrm{~cm}$. Su tronco, muy grueso y leñoso, resistía exitosamente a la presión del trapiche de madera que, de tal manera, extraía relativamente poco jugo. Hasta la divulgación de

(17) Hay que mencionar que los bosques de Cuba tenían gran fama ya desde los tíempos de Colón. Los historiadores cubanos citan frecuentemente las sentencias del diario de Colón sobre la riqueza de Cuba: "Dize el Almirante que nunca tan hermosa cosa vido, lleno de árboles todo cercado el río, fermosos y verdes y diversos de los nuestros, con flores y con su fruto cada uno de su manera; avía gran cantidad de palmas de otra manera que las de Guinea y de las nuestras, de una estatura mediana y de los pies sin aquella camisa y las hojas muy grandes, con las cuales cobijan las casas; la tierra muy llana.» Cristóbal Colón, Diario. Relaciones de viajes. Madrid, SARPE, 1986, pág. 40.

(18) Ya en el segundo decenio del siglo XIX, se quejaron algunos autores (comp., por ejemplo, el artículo de José de ARANGo, "Jobo", en: Memorias de la Sociedad Económica de Amigos del Pais. La Habana, 181.7, págs. 264-273) de que se quemaban los bosques isleños y que, al mismo tiempo, se importaba una cantidad creciente de las tablas de pino y ciprés de los EE UU. Estos críticos olvidaron, no obstante, una cosa importante. En este comercio, un cierto papel tuvo también la necesidad de utilizar para la fabricación de cajas tales maderas que no comunicasen su olor al azúcar. La mayoría de las maderas preciosas de Cuba no correspondían a esta condición. José de Arango propuso aprovechar para la fabricación de las cajas de jobo, pero sin éxito. Sobre el comercio con la madera ver L. MARRERo, [2], t. 12, pág. 171.

(19) Ibidem, pág. 173.

R. I., 1996, n.o 207 
los trapiches metálicos durante el siglo xIx significó la generalización de Otahití en las plantaciones cubanas. Comparando esta especie con la criolla, los terratenientes apreciaban paradójicamente ante todo la abundancia de bagazo, utilizado en muchos ingenios de la isla como combustible, a menudo en combinación con la leña. Con los cambios de la maquinaría de los ingenios, la caña de Otahití predominó sobre todas las demás variedades. Uno de los factores más importantes en este proceso fue, evidentemente, el aporte para la solución del problema de combustible en las casas de calderas.

Los propietarios de los ingenios comprendieron que la escasez del combustible era un peligro enorme para la prosperidad de la industria azucarera. Uno de ellos, José Pizarro y Gardín, dueño del ingenio El Triángulo, comentaba al respecto: «...nadie ignora que la más aguda enfermedad, la enfermedad mortal para nuestros ingenios es la falta de montes, pues la que se llama comúnmente cansancio de los terrenos, tiene tantos remedios aquí como en la vieja Europa, y no sin ejemplo ya en algunos puntos de América» (20).

Los portavoces de la sacarocracia buscaron ante todo el camino para resolver el primer asunto. José Pizarro propuso la formación de grandes plantaciones de palmas reales en los

(20) José PiZarro y GardíN, «Industria agrícola. Reposición de los bosques que se consumen anualmente en el combustible de los ingenios», en: Memorias de la Real Sociedad, n. 6, diciembre 1846, pág. 373. Aquí, Pizarro menciona otro problema relacionado con la liquidación de los bosques que inquietó a los terratenientes criollos. M. Moreno Fraginals escribió sobre este factor: "La muerte del bosque era también en parte, a largo plazo, de la fabulosa fertilidad de la Isla. Esta era una larga experiencia azucarera antillana que nuestros sacarócratas conocían. El trabajo esclavo obligaba a utilizar técnicas rudimentarias de bajísimo rendimiento industrial. Para compensar las terribles deficiencias fabriles se buscaron los más altos rendimientos agrícolas. Pero a su veż este rendimiento agrícola no era en forma alguna el resultado de la utilización racional de los suelos sino de la increíble riqueza de las tierras vírgenes recién desmontadas. Muerto el bosque, las primeras siembras produjeron corrientemente mucho más de 120.000 arrobas de caña por caballería (102 t/ha.). Cortando anualmente los cañaverales, descuidando el transporte y vire de paja, sin utilización de regadíos ni abonos, bajan anualmente los rendimientos agrícolas. Al llegar a un punto crítico se abandona la tierra, se tumba un nuevo bosque y otra vez vuelven las fabulosas cifras de producción cañera." M. MoRENo FraginaLs, [4], vol. I, pág. 161. 
terrenos poco propios para las plantaciones de caña de azúcar que pudieran suministrar a los ingenios no sólo abundante leña, sino también sus hojas y ramales diciendo:

«pues así volvamos á nuestra plantación de palmas, hermosas y legítimas hijas de nuestro fértil suelo, ellas parecen destinadas á salvar una gran parte de nuestros bosques, á salvarnos también de las consecuencias que se siguen á su devastación, y á indultarnos de un penoso trabajo y de un no pequeño gasto, ofreciéndonos con regularidad constante una cantidad de combustible que puede sustituir con ventajas á cualquier otro, para el uso de nuestros ingenios, tanto en los fogones de las máquinas como en reverberos de los trenes de hacer el azúcar. Mientras dura la abundancia, no piensa el hombre en la necesidad de las economías, pero el tiempo corre, las circunstancias cambian, y se deja entonces sentir el bien perdido, y los daños que hubieran podido prevenirse» (21).

En cuanto a esta proposición, Pizarro tenía sus precursores ya en los años treinta. En las Memorias de la Real Sociedad aparecieron varios artículos sobre el problema, como fueron los de Andrés de Zayas "Observaciones sobre los ingenios de esta isla» donde se incluían entre otros, "Los desórdenes que se advierten en los ingenios». Uno de los mayores problemas para Zayas era la facilidad con que los propietarios desmontaban sus terrenos y para lo cual ofreció una solución simple:

«Nada es más fácil que formar un monte, en el peor terreno de la finca, donde nada pueda sembrarse por malo, se plantan guácimas, paraísos, guayabos y otros árboles, que siendo demasiado vivaces, vienen con facilidad y duran muchos años, si en lugar de hacha ó del machete, se adopta ó emplea la sierra para cortarlos á una altura proporcionada. A los tres años está formado un monte, y con la leña que se saque de él, bastará para alimentar a nuestros trenes, respecto que casi no las necesitan, pues que mucho mejor andan con paja, bagazo y brusca; por lo que pudieran excusarse, si en la finca no hubiera otros objetos á que aplicarlos, y aun con

(21) José Pizarro y Gardín, [20], pág. 375 y sigs,

R. I., 1996, n.o 207 
todo, se pudiera absolutamente pasar sin ellos, como sucede en algunos ingenios donde no se encuentra ni un sólo cuge» (22).

Zayas destacó que en el terreno el bosque jugaba otro papel esencial como era el servir de protección contra los rayos del sol. En este contexto el autor subrayó: «La siembra de dichos árboles se hará delineando antes el terreno, así para que quepan más como para que guardando proporción en sus distancias, puedan extenderse mejor sus ramas y dar más cantidad de leña. Con ellos disminuiremos los funestos efectos de la seca, y tendríamos el vehículo más eficaz de la frescura que necesitamos, pues con su falta crece la reverberación de los rayos solares, y cada vez va estirilizando más el terreno, privándole por este medio del abono que le proporciona el despojo de estos mismos árboles. Debiera por lo tanto conservarse una línea de monte en todo el círculo de la hacienda, y además de las ventajas que produciría su inmediación á todas partes, se tendrían resguardadas sus plantaciones de los vientos y del daño que les hacen los caminantes ó los vecinos» (23). Para Zayas, la plantación representaba un complejo que debía tener su plan del aprovechamiento no sólo para su propietario, sino también para el bien de la sociedad, si es que lo podamos decir de esta manera: «Bien visto no debería haber un palmo de tierra que no estuviese cultivado ó empleado en alguna cosa que fuera útil, supuesto que con poco trabajo todo se conseguiría. La tierra que no está sembrada de caña, ni destinada á potrero, deberá conservarse de monte; ya, no derribando los que existían, ya plantándolos de nuevo, porque está demostrada la facilidad con que pudiera conseguirse; cesando por consecuencia el abuso en que incurren nuestros mayorales de sembrar siempre en tierra nueva, abandonando las viejas, aun cuando todavía pueden producir. El interés público, no menos que el privado, se empeñan en su logro, y es

(22) Andrés ZAYAS, "Observaciones sobre los ingenios de esta isla», en: Memorias de la Real Sociedad Patriótica de La Habana. 1836, tomo I, pág. 255 y sigs.

(23) Ibidem, pág. 256. 
de esperar que se remediará el mal, pues aún no ha llegado á su colmo» (24).

No sorprende mucho que también uno de los más importantes defensores de los intereses de la sacarocracia criolla, José Antonio Saco, presentara repetidamente su opinión sobre este fenómeno y propusiera su solución. En la introducción a uno de sus artículos sobre el problema menciona la memoria sobre la necesidad de la conservación de los bosques en la isla de José Ricardo O'Farrill del fin del siglo xviII donde el autor escribió sobre el peligro de la deforestación total de los alrededores de La Habana:

"Una experiencia dolorosa ha venido a cumplir tan triste vaticinio, y el viajero que recorre los talados campos de aquella fértil región, al paso que compadece la suerte infeliz de tantos propietarios, maldice la mano bárbara que causó tales estragos. Hecho está ya el daño; más en parte puede remediarse; y aun cuando así no fuese, nosotros nunca callaríamos, pues sabemos que el mal que pesa hoy sobre los habitantes de La Habana, aún no sirve de ejemplo a los pueblos del interior de la isla. Imperfecta como está en ellos la agricultura, y entregados casi exclusivamente a la cría de ganados, no conocen todas las ventajas que disfrutan con la posesión de sus bosques, ni menos se precaven de las fatales consecuencias que traerá su destrucción» (25).

En este contexto Saco subrayó: "No hay que alucinarse con la idea lisonjera, de que la isla tiene todavía bosques inmensos, y que éstos serán suficientes para abastecer todas las necesidades. Volvamos la vista a la memoria citada, y observemos con su autor, que en el año de 1766, los montes sólo distaban de La Habana de cinco a seis leguas en contorno; en 1797, es decir treinta y un años después, ya se habían retirado de 16 a 20; y en el día no se encuentran por algunas partes, ni aún a la distancia de 40; de manera que, en poco más de medio siglo se ha verificado una transformación tan notable» (26). La defores-

(24) Ibidem.

(25) José Antonio SACO, "Montes o bosques en la Isla de Cuba", Mensajero Semanal del 25 de agosto de 1828, citado según Colección..., t. I, pág. 45.

(26) Ibidem, pág. 46.

R. I., 1996, n. 207 
tación la atribuía directamente a la industria azucarera mostrando que en el período de la expansión de la ganadería, la isla no conocía este mal. Constató racionalmente que de parte de los terratenientes no se podía esperar una conducta razonable en cuanto a los bosques, es decir, la limitación de la industria azucarera, y presentó al público ciertas proposiciones de cómo minimizar el impacto de la ampliación de las plantaciones al paisaje cubano: "Afortunadamente ya se han hecho algunas tentativas para formar bosques, pero como su necesidad donde más se siente, es en los ingenios, los dueños de éstos no han dirigido sus miras á los árboles de construcción, sino á aquéllos, que al paso que crecen rápidamente, se producen con facilidad. Con este fin, han propuesto algunos la caña brava, otros el mango, y aun no han faltado, quienes hayan pedido á este país, la semilla de la falsa acacia, para repartirla entre varios hacendados, é introducir en la isla un árbol tan interesante» (27). Asimismo, apuntaba las ventajas de este árbol, no sólo la rapidez de su crecimiento, sino también el factor de mucha importancia para los ingenios: «...es buen combustible, y ofrece la ventaja de arder bien, aun desde el mismo día en que se corta» (28). Alabando también otras cualidades de la madera de este árbol, volvió, no obstante, a su primer interés: "Usase también para armaduras de sillas y otros muebles de lujo; para clavos, cercas y combustibles. Esta quizá será la propiedad que le hará más recomendable en la isla de Cuba, pues si por una parte abundamos de madera de construcción, por otra carecemos de combustible en muchos de nuestros ingenios» (29).

Otro de los autores que también abordaron el tema fue Vicente Vázquez Queipo, intendente de la Real Hacienda, en su Informe fiscal sobre fomento de la población blanca en la Isla de Cuba y emancipación progresiva de la esclava, donde encontró una correlación estrecha entre el estado de los montes, el desarrollo de la agricultura y de la población de la isla:

(27) Ibidem.

(28) Ibidem, pág. 47.

(29) Ibidem, pág. 48. 
"Si éstos son necesarios para el desarrollo de la agricultura, de que depende como hemos dicho la población, no lo son menos los montes, que no sólo la proveen las maderas necesarias para la construcción, sino que modifican benignamente el clima con su poderosa acción sobre la atmósfera, y las frecuentes lluvias que producen ó atraen cuando menos. A su falta, ó mejor dicho, á la destrucción de los vigorosos y seculares bosques, descuajados para el cultivo del azúcar, se deben las frecuentes secas y el trastorno de las estaciones que empezamos á experimentar; y seguro es que si prontamente no se pone un dique á este espíritu egoísta, que todo lo sacrifica al presente sin cuidarse del porvenir, no está lejos el día en que la isla de Cuba sufra la suerte de la antigua y otras pequeñas Antillas desprovistas por arboleda, donde no se conoce ni puede sostenerse otra clase de cultura que caña, no exenta, á pesar de su grande resistencia, del efecto de las grandes secas que frecuentemente experimentan. Si en todos los países son útiles los montes, en ninguno son más necesarios que en los climas intertropicales para templar los ardores del sol, cuya acción directa y continuada sobre el suelo, lo deseca, empobrece y hace casi inhabitable. A las autoridades corresponde poner en observancia los reglamentos que se juzguen convenientes para la conservación de los montes; así como á la Real Junta y á la Sociedad económica ilustrar al público sobre los métodos, y mejorar especies de árboles, con que han de poblarse» (30).

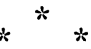

De la reacción de los terratenientes en la segunda mitad de los años cuarenta se deduce que esta capa social consideraba esa problemática como una seria amenaza para su futuro. El licenciado Lúcas Arcadio de Ugarte, secretario de la Sección de Agricultura y Estadística de la Real Sociedad, leyó en la reunión de la Sociedad un material alarmante, en el que llamaba la atención sobre la necesidad de impedir la destrucción total de los montes cubanos: "La sección ha considerado que es pre-

(30) V. VÁzQuez QuEIPO, Informe fiscal sobre fomento de la población blanca en la Isla de Cuba y emancipación progresiva esclava. Madrid, 1845, pág. 51 . 
ciso establecer alguna ley que arregle aquélla y la metodice, para libertarnos de la carencia absoluta de que nos amenazan á la vez, el carbón, los vapores, los caminos de hierro y las siembras de cañas; y al tratar de ello, no ha pensado de manera alguna atacar la propiedad particular que tanto debe respetarse, mas no ha creído sin embargo que se la tacharía si abogaba, porque, ya que se destruyen los espesos y útiles bosques que forman la excelencia de nuestros campos, se repongan á la vez para que jamás nos falten» (31). Los autores de la memoria evaluaban que en el transcurso de tres o cuatro años los bosques cubanos dejarían de existir expresando, sin embargo, cierta esperanza en la sabiduría de los terratenientes. En esta ocasión dijo: "...los hacendados despierten del letargo en que yacen, y conozcan el lamentable descuido con que permiten sin orden el uso de sus destructoras hachas; descuido que llorarán sus hijos cuando hereden extensas campiñas desflojadas de las bellas y sólidas maderas de que siempre estuvieron cubiertas nuestras fértiles montañas» (32).

No obstante, la voz de estos intelectuales tuvo poco eco en la capa de los terratenientes. Hay que decir que no fue sólo el azúcar el elemento que arrasó los bosques, como escribió M. Moreno Fraginals (33). También los cafetales necesitaban terrenos desprovistos de árboles. En un extenso artículo sobre el cultivo del café (34) de 1836 se dedicaba gran atención al "desmonte» del terreno (35). Mencionando que en la segunda mitad de los años treinta no existieron bosques a la distancia de 12 ó 14 leguas de La Habana, subrayaba la necesidad de un comportamiento razonable en cuanto a los bosques, es decir, no talar todos los árboles en el mismo momento, sino gradual-

(31) «Memoria sobre los trabajos en que se ha ocupado la Sección de Agricultura y Estadística en el año próximo pasado» leída por su secretario el Ldo. don Lúcas ARCADio DE UgarTe, en: Memorias de la Real Sociedad, t. I, n. 3,1846 , pág. 139 .

(32) Ibidem.

(33) M. Moreno Fraginals, [4], t. I, pág. 163.

(34) "Historia del café y sus propiedades», en: Memorias de la Real Sociedad Patriótica de La Habana, t. 2, La Habana, Oficina del Gobierno y Capitanía General, 1836, págs. 255-274, 313-330, 403-414.

(35) Ibidem, págs. 268-271. 
mente para poder aprovechar toda la madera: «Puede aprovecharse de la tumba toda la madera que se necesite así para las fábricas provisionales como las que deben construirse después; y como es importante é indispensable sembrar algunas viandas para ayudar á la subsistencia de los trabajadores y con la brevedad posible, se procurará limpiar el terreno usado del fuego después de separadas las maderas más notables y preciosas» (36).

Por otra parte, aconsejaba a los lectores no talar todos los árboles en el terreno, con el argumento de que si bien las cosechas del café de las plantas que crecían en la sombra no eran tan grandes, "pero á lo menos son siempre iguales» (37). Además, la tierra de los cafetales sin árboles, igual que el terreno de las plantaciones de caña, se agotaba rápidamente. La deforestación causaba, por una parte, una grave erosión y, por la otra, la sequía de grandes regiones de la isla, de la disminución de la fertilidad de la tierra.

Uno de los problemas fundamentales de la expansión económica de Cuba en la primera mitad del siglo xIx fue, pues, el ansia de la ganancia inmediata que pesó más que la amenaza de la destrucción en el futuro. Ello fue la principal causa de la liquidación de los bosques cubanos a pesar de las advertencias de los portavoces realistas de la sacarocracia criolla, acelerándose durante los años treinta y cuarenta la esquilmación de los bosques en la isla. Si a fines del siglo xviII los montes disminuían en 6.710 ha. anualmente, en 1819 era en 13.420 ha., en 1830 en 26.820 ha. y en 1844 en 53.680 ha. (38). Cada año desaparecían miles y miles de caobas, palmas reales y otros símbolos de la naturaleza cubana, convirtiéndose los famosos bosques en leyenda. Las exhortaciones a cambiar esta política tenían el mismo resultado como los llamamientos a cambiar la política en la esfera social de la colonia, especialmente en cuanto a la población de color (39). Esta pesadilla se solucio-

(36) Ibidem, pág. 269.

(37) Ibidem, pág. 270 y sigs.

(38) M. Moreno Fraginals, [4], pág. 158.

(39) En cuanto a la necesidad de los cambios en la esfera social de la colonia, especialmente en lo que tocó a la esclavitud existió en la sociedad colonial y en la metrópoli gran cantidad de las opiniones diferentes. Una parte de 
nó, en cierta medida, por los acontecimientos de la segunda mitad del siglo XIX. No obstante, los cambios del medio ambiente relacionados con el desarrollo económico continuaron e influyeron profundamente en el aspecto del paisaje cubano.

los oponentes del sistema basado en el trabajo de los esclavos atacó las condiciones existentes pidiendo los cambios profundos, ver, por ejemplo, J. Antonio SACO, [11]. Como ejemplo de las ideas diferentes ver las de M. TORRENTE: "Mas como nuestros deseos son de que se aumente en lo posible la gente de color, y si cabe, en escala mayor que la blanca, por ser la más necesaria para las labores agrícolas, en las que consiste la principal riqueza del país, no cesaremos de recomendar á los dueños de esclavos que dediquen toda su atención á establecer los mejores métodos de que se propague esta especie. Cuando entraban libremente los esclavos africanos, ó bien por el antiguo asiento ó contrato que la Inglaterra había estipulado con la España para proveer sus colonias de estas gentes, que en aquellos tiempos eran considerados como mercancía, o bien cuando concluido aquel contrato siguieron los especuladores nacionales abasteciendo por su propia cuenta los mercados, no sólo no se necesitaba ocuparse de fomentar la propagación y educación de estos operararios, sino que aquélla era en cierto modo contraria y perjudicial, considerada bajo el aspecto mercantil.

Para poder empezar á sacar algún partido lucrativo de una de estas crías, se necesitaba emplear diez o doce años en su cuidado y manutención; se necesitaba privarse de los trabajos de la madre, si no todo el tiempo de su embarazo, por lo menos una gran parte de él; se necesitaba correr las eventualidades y los riesgos inherentes á los partos, en que no pocas se desgraciaban: así que, sumado el lucro cesante, el daño emergente y los gastos adicionales, tenía mas cuenta cegar ó esterilizar las fuentes de esta clase de producción, que fomentar su desarrollo, cuando se ofrecía á los cálculos económicos mayor ventaja con la fácil adquisición de un varón en toda su virilidad y robustez por cuatrocientos duros, y de una hembra por trescientos.

...En honor de la justicia y de la verdad, debemos confesar que ya muchos hacendados han construido en sus fincas, con los mejores resultados, excelentes enfermerías y habitaciones para los criollitos, los cuales durante el día y mientras que sus madres se hallaban ocupadas en las labores del campo, están al cuidado de negras ancianas, que al mismo tiempo y por mucha experiencia son las matronas de los partos.

Deseamos que se generalicen estos métodos y ese afán por la reproducción y aumento de una especie tan importante y aun necesaria, y que el gobierno la estimule y promueva hasta el punto de conceder algunos premios á los que justifiquen haber hecho mayores adelantos, habida cuenta el número de sus esclavos. Atendidas las condiciones del clima, producciones y necesidades, debería seguir igual progreso el aumento de la población blanca con la de color; nos parece que económica y aun políticamente hablando, tan perjudicial sería que la primera creciese, quedando atrasada la segunda, como que ésta tomase mucho vuelo, decayendo aquélla.» M. TORRENTE, [5], pág. 151 y sigs. 
Un paisaje que en el siglo xIX era totalmente diferente del que conocieron los habitantes de la isla a finales del siglo precedente cuando algunos de ellos, como el mencionado José Ricardo O'Farrill, presentaron sus temores en cuanto al futuro de los bosques de la isla pidiendo en vano una política razonable por parte de la sacarocracia insular en esta esfera.

The explosive development of Cuba's sugar industry in the 1st half of the 19th century had a profound effect on the environment. First among the white creoles' concerns was the rapid deforestation. Many of them, however, also objected to the industry's growth on the grounds that it was causing a substantial increase of the black population on the island.

R. I., 1996, n. ${ }^{\circ} 207$ 